\title{
Poros Nucleares y Función Celular en Epitelio Mamario
}

\author{
Nuclear Pores and Cellular Function
}

\author{
R. Cornejo*; O. Garrido"*; R. Jaramillo**; E. Vergara*; P. Lermanda* \& Y. Gatica**
}

CORNEJO, R.; GARRIDO, O.; JARAMILLO, R. ; VERGARA, E.; LERMANDA, P. \& GATICA, Y. Poros nucleares y función celular en epitelio mamario. Int. J. Morphol., 33(4):1269-1272, 2015.

RESUMEN: El presente artículo tiene como objetivo central evidenciar la interesante relación que se establece entre la función celular y el número de poros nucleares, relación que modula el activo intercambio nucleo-citoplasmatico en distintas etapas del ciclo celular de la estirpe HC11.

PALABRAS CLAVE: Poros nucleares; Diferenciación Celular; Células mamarias.

\section{INTRODUCCION}

En las células eucarióticas el intrincado mecanismo de mantener los organismos en su ciclo vital está determinado por una activa y continua comunicación entre estructuras y/o emisiones moleculares versus componentes citosólicos, es decir, una relación directa entre constituyentes nucleares con organelos citoplasmáticos actuando en directa y estrecha colaboración (Terry et al., 2007).

Recordando que en el núcleo eucariótico se encuentra depositada la información genética en forma de ADN responsable de codificar las moléculas que regirán los mecanismos propios del ciclo vital celular, el material genético será enzimáticamente replicado, transcrito a moléculas de RNA originando el RNAm, RNAt y el RNAr a expensas de enzimas específicas para cada evento molecular (Forero \& Urcuqui, 2004; Beck et al., 2007).

Los dos primeros tipos de RNA sintetizados abandonarán el compartimento nuclear hacia el citosol para participar luego en la traducción o síntesis de proteínas, mientras que el RNAr participará en la biogénesis ribosomal abandonando el núcleo y en el citoplasma adherirse a las membranas de retículo endoplasmático originando el RER o permanecer libres en el citoplasma (Audhya et al., 2007) y en ellos donde se sintetizarán las proteínas y enzimas para los procesos celulares algunas de ellas como la DNA polimerasa, la RNApolimerasa, las histonas, factores reguladores de la expresión génica, etc. volverán al interior del núcleo para realizar una determinada e importante funcionalidad (Montanaro, 2008).
De igual manera, es necesario recordar que todas las moléculas que pertenecen a los distintos organelos citoplasmáticos poseen información proveniente del compartimento nuclear.

El transporte entre los compartimentos nuclear y citoplasmático se realiza a través de la envoltura nuclear, membrana nuclear o carioteca, formada por dos unidades de membrana concéntricas, la externa o citoplasmática que posee ribosomas adheridos y la interna o nuclear con lámina nuclear, conjunto de filamentos intermediarios que le confiere estabilidad a la estructura. Entre ambas membranas existe un espacio de 25-40 nm que constituye la cisterna perinuclear, la cual se caracteriza por presentar poros nucleares, espacios circulares que dejan las membranas al unirse e interrumpiendo su continuidad de trecho en trecho con un diámetro de unos $80 \mathrm{~nm}$, estableciéndose comunicaciones entre el cito y el nucleoplasma.

Las moléculas menores a $50 \mathrm{kDa}$ atraviesan los poros mediante simple difusión, en cambio moléculas mayores requiere de receptores específicos ubicados en los poros, denominados carioferinas, (Antonin, 2009)

Numerosos trabajos al respecto indican que el número de poros varía, de unas células a otras, entre 2 y 60 por $\mu \mathrm{m}^{2}$, y por tanto, sería posible visualizar un equivalente hasta 3000-4000 poros por núcleo (Maeshima et al., 2011)

\footnotetext{
* Depto. de Ciencias Básicas, Facultad de Medicina, Universidad de La Frontera, Temuco, Chile.

** Instituto de Ciencias Marinas y Limnológicas, Universidad Austral de Chile, Valdivia, Chile.
} 
Además ha sido demostrado que la envoltura nuclear posee poros o complejos de poro los que se incrementan en medida que la función celular es más activa (Hoelz et al., 2011).

Por otra parte, pero con directa relación a lo planteado entre los complejos mecanismos mediante los cuales las células darán origen a tejidos diferenciados responsables por diferentes funciones en los organismos pluricelulares encontramos la especialización, proceso que dirige a una célula hasta un estado de diferenciación morfológica y funcional y donde finaliza con la diferenciación celular, apareciendo modificaciones celulares profundas relacionadas con alteraciones cualitativa y cuantitativas de organelos y otros componentes celulares y donde, naturalmente, esta célula aumenta la eficiencia para ejecutar una función específica, mecanismos todos que están caracterizado por la activa expresión de ciertos genes que se traducen en la síntesis de una o más proteínas específicas (Paniagua et al., 2007).

Para corroborar los antecedentes expuestos contando la microscopía electrónica de transmisión que permitió micrografiar células mamarias de rata mantenidas en cultivo tanto en estadio de proliferación HC11 GM (activadas por el factor de crecimiento epidérmico) como en estado de diferenciación HC11 IM (estimuladas con hormonas lactogénicas: hidrocortisona, prolactina e insulina) (Cornejo, 2004).

\section{MATERIAL Y METODO}

Células pertenecientes a los tipos HC11 GM y HC11 IM fueron obtenidas de sus respectivas cámaras de cultivo, centrifugadas por espacio de 50 segundos a $13.500 \mathrm{~g}$ en una solución de $\mathrm{NaCl} 150 \mathrm{mM}$ en tampón fosfato $0,1 \mathrm{M}$ y el pellet recuperado es procesado para microscopía electrónica de transmisión, donde a las muestras se le adicionó una solución de glutaraldehído $2 \%$ en tampón fosfato 0,15 M, pH 7,2 y se mantuvo a temperatura ambiente por 2 horas. Luego, fueron sometidas a un lavado en solución de $6 \mathrm{~g}$ de $\mathrm{NaCl}$ y $73 \mathrm{~g}$ de sacarosa, disuelto en 1 litro de agua destilada.

La post-fijación se realizó con tetróxido de osmio $1 \%$ disuelto en la solución antes descrita durante una hora a $40{ }^{\circ} \mathrm{C}$ y acetato de uranilo $0,5 \%$ por $18 \mathrm{~h}$. Luego de lavado el material fue deshidratado en concentraciones crecientes de acetona (30 a 100\%) e incluido en Araldita 6005. Se obtuvieron cortes ultrafinos de aproximadamente $70 \mathrm{~nm}$ de grosor, los que fueron tratados con acetato de uranilo $2 \%$ durante 40 minutos y citrato de plomo $0,5 \%$ por 10 minutos.

Las muestras fueron finalmente estudiadas y microfotografiadas en un microscopio electrónico Phillips EM 300.
A partir de los bloques para microscopia electrónica fueron obtenidos cortes ultrafinos desde los cuales se micrografiaron las células HC11 GM y HC11 IM con un aumento final de hasta $8.500 \mathrm{X}$. en un microscopio electrónico Phillips EM 300, permitiendo realizar un estudio de las características ultraestructurales de las células mediante el uso de un Software análisis de imágenes SIGMA SCAN-PRO 5.0.

A partir de las imágenes de los núcleos se procedió a realizar un conteo del número de poros presentes en las imágenes de cada uno de los dos tipos celulares estudiados para lo cual se contabilizaron solo aquellos en que fue posible evidenciar su conexión tanto con el citoplasma como con el contenido nuclear. Adicionalmente se realizó la medición del perímetro y el diámetro del núcleo con la finalidad de realizar una estimación mas precisa del número de poros por unidad de área considerando que se ha demostrado que existiría entre 2 a 60 poros por cada $\mathrm{mm}^{2}$ para posteriormente, mediante la utilización de la ecuación matemática que permite calcular la superficie de una esfera $\left(4 \pi r^{2}\right)$ se procedió a realizar una estimación teórica del número de poros por núcleo estudiado (Fahrenkrog \& Aebi, 2003).

\section{RESULTADOS}

En laas primeras mediciones considerando las micrografías electrónicas hemos determinado claras diferencias morfológicas y en el número de poros nucleares que existen entre ambos tipos celulares situación que se evidencian en las Figuras 1 y 2, y que se describen en las Tablas I y II.

En este contexto, cuantificamos que el número de poros en primera dimensión perteneciente a la célula en proceso de diferenciación es de 55 poros nucleares efectivamente mayor que el evaluado en la célula que experimenta el mecanismo de proliferación que solamente alcanza a 16 poros, existiendo claramente una diferencia significativa en el número de poros nucleares.

Basado en los datos anteriores y usando los criterios descritos en Material y Método pareció importante determinar funcionalidad celular, realizar cálculos tendiente a precisar, aunque aproximadamente, el número de poros nucleares que estas células poseen considerando esta vez su estructura tridimensional pudiendo cuantificar que HC11 GM contiene alrededor de 153 poros en su membrana nuclear.

De igual manera teniendo como base el método anteriormente descrito y por el contrario fue calculado el número de poros nucleares para la célula en estadio de diferenciación donde se cuantificaron 409. 


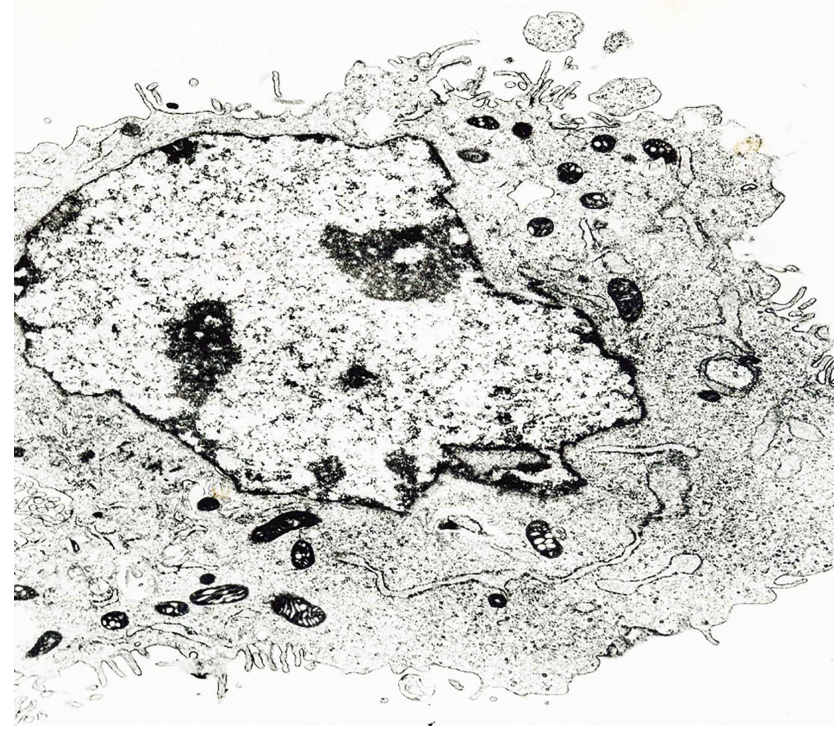

Fig. 1 Microfotografia electrónica de transmisión perteneciente a célula de glándula mamaria de rata en estadio de proliferación HC11 GM $(8.500 \mathrm{X})$.

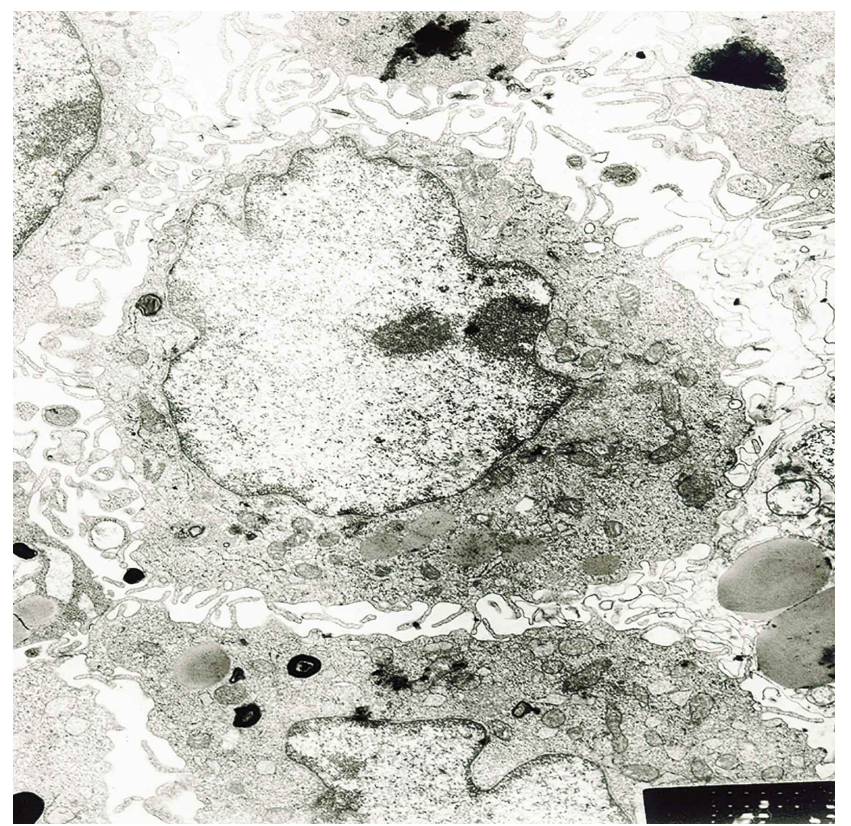

Fig. 2. Microfotografia electrónica de transmisión perteneciente a célula de glándula mamaria de rata en estadio de diferenciación HC11 IM (8.500 X).
Tabla II. Fracciones volumétricas expresadas en porcentaje correspondiente a tipo de cromatina y nucléolo evaluadas en células mamarias en proceso de proliferación y diferenciación.

\begin{tabular}{lcc}
\hline Componente Celular & HC11 GM & HC11 IM \\
\hline Eucromatina & $90 \%$ & $95 \%$ \\
Heterocromatina & $10 \%$ & $5 \%$ \\
Nucleolo & $11 \%$ & $10 \%$ \\
\hline
\end{tabular}

\section{DISCUSION}

Estos resultados nos indican que las células en proceso de diferenciación presentan un mayor número de poros nucleares en comparación de aquellas que se encuentran en fase de proliferación y ellos son consistentes con el estado de desarrollo en el que se encuentran las células HC11 IM las cuales tienen activados los mecanismos propios de la diferenciación celular, es decir, sintetizando y exportando Beta Caseína, la principal proteína de la secreción láctea. y donde esta síntesis y secreción de leche genera, claro está, un evidente incremento en los volúmenes celulares de ribosomas implicando el consiguiente transporte tanto del RNAr como igualmente del RNAm desde el núcleo al citoplasma, portando la información génica para la síntesis de dicha proteína.

De igual manera, esta célula en fase de diferenciación presenta mayor volumen tanto de lisosomas como de filamentos intermediarios de citoqueratina, constituyente proteico del citoesqueleto donde para la síntesis de ambos constituyentes citoplasmáticos se deberá trasladar al citosol desde el núcleo los respectivos genes para las correspondientes enzimas lisosomales y de la citoqueratina. De igual modo, pero en menor escala es necesario también considerar en este transporte núcleo-citoplasmático los genes nucleares que codificarán en el citosol las distintas proteínas mitocondriales que complementaran la dotación proteica del organelo sumadas a las que codifica su propio material genético (Cornejo).

A pesar de la información que aquí se proporciona es posible argumentar como conclusión que en relación a la dinámica de la membrana nuclear y sus poros en las etapas del

\begin{tabular}{lcc}
\hline Tipo celular & HC11 GM & HC11 IM \\
\hline Número de poros $\left(1^{\mathrm{a}} \mathrm{D}\right)$ & 16 & 55 \\
Diámetro nuclear & 12 & 8 \\
Radio nuclear & 6 & 4 \\
Superficie nuclear $\left(\mu^{2}\right)$ & 542 & 201 \\
Perímetro nuclear $(\mu \mathrm{m})$ & 47 & 27 \\
$\mathrm{~N}^{\mathrm{o}}$ poros/unidad superfic. & $16 / 47=0,34 \mathrm{poros} / \mu \mathrm{m}$ & $55 / 27=2,30 \mathrm{poros} / \mu \mathrm{m}$ \\
Poros/superficie & $0,34 \times 542 \mu^{2}$ & $2,30 \times 201 \mu^{2}$ \\
Total poros/ célula & 153 & 409 \\
\hline
\end{tabular}

Tabla I. Evaluación de parámetros nucleares pertenecientes a células mamarias en proceso de proliferación y diferenciación. 
ciclo celular, la información al respecto es escasa. Sin embargo, Anderson et al. (2009) plantean la necesaria existencia de grandes cantidades de complejo de poros nucleares (NPC) en las diferentes etapas del ciclo de la célula, donde la demanda transcripcional de DNA es elevada y donde un claro ejemplo lo constituyen los oocytos los cuales acumulan gran cantidad de NPC para prepararse a las rápidas mitosis que existen en las fases de desarrollo temprano.

Con directa relación a la problemática planteada ya en la década del ochenta los científicos elaboraron investigaciones respecto a determinar que en los núcleos interfásicos existían sitios específicos o determinados territorios ocupados por el material cromatínico, situación que en la actualidad aparece como absolutamente demostrado (D’Angelo et al., 2009).

Efectivamente, la disposición de los territorios cromosómicos son consecuencia funcional directa para la regulación de la expresión génica, de este modo, se ha demostrado que genes con dominios ricos en territorios ocupan la región interna del núcleo y por el contrario genes que exhiben pobres dominios se localizan en la periferia de la estructura nuclear. De igual manera, genes transcripcionálmente activos tienen tendencia a residir en el interior del núcleo contrastando con aquellos genes transcripcionalmente inactivos (Dechat et al., 2008).

Un claro ejemplo de esta arquitectura nuclear se presenta durante las etapas del desarrollo donde los dominios de la cromatina que contiene genes activos en transcripción ocupan territorios cromosómicos en el centro del núcleo de células embrionarias humanas y del mismo modo, los genes que pertenecen al complejo de diferenciación epidérmica se encuentran en forma descondensados y ubicados periféricamente (Bártová et al., 2008).

Estos hechos estarían demostrando entonces que existe una determinada distribución cromosómica que guardaría directa relación de continuidad con los respectivos poros nucleares en espera de recibir tanto el resultado de los procesos de transcripción génica como del correspondiente traslado de diversas moléculas hacia el citosol.

CORNEJO, R.; GARRIDO, O.; JARAMILLO, R. ; VERGARA, E.; LERMANDA, P. \& GATICA, Y. Nuclear pores and cellular function. Int. J. Morphol., 33(4):1269-1272, 2015.

SUMMARY: The main objective of this article is related to the study of different existing relationships between cellular function and the number of nuclear pores in order to explain the amount of nuclear-cytoplasmatic exchange through $\mathrm{HC} 11$ cell cycle stages.

KEY WORDS: Nuclear Pores; Cellular Differentiation; Mammary cells.

1272

\section{REFERENCIAS BIBLIOGRÁFICAS}

Anderson, D. J.; Vargas, J. D.; Hsiao, J. P. \& Hetzer, M. W. Recruitment of functionally distinct membrane proteins to chromatin mediates nuclear envelope formation in vivo. J. Cell Biol., 186(2):183-91, 2009.

Antonin, W. Nuclear envelope: membrane bending for pore formation? Curr. Biol., 26;19(10):R410-2, 2009.

Audhya, A.; Desai A. \& Oegema, K. A role for Rab5 in structuring the endoplasmic reticulum. J. Cell Biol., 178(1):43-56, 2007.

Bártová, E.; Krejcí, J.; Harnicarová, A.; Galiová, G. \& Kozubek, S. Histone modifications and nuclear architecture: a review. J. Histochem. Cytochem., 56(8):711-21, 2008

Beck, M.; Lucic, V.; Förster, F.; Baumeister, W. \& Medalia, O. Snapshots of nuclear pore complexes in action captured by cryo-electron tomography. Nature, 449(7162):611-5, 2007.

Cornejo, U. R. Morphometric and ultrastructural analysis of components associated to protein synthesis in normal and transformed mammary cells. Int. J. Morphol., 22(3):221-4, 2004.

D’Angelo, M. A.; Raices, M.; Panowski, S. H. \& Hetzer, M. W. Age-dependent deterioration of nuclear pore complexes causes a loss of nuclear integrity in postmitotic cells. Cell, 136(2):284-95, 2009.

Dechat, T.; Pfleghaar, K.; Sengupta, K.; Shimi, T.; Shumaker, D. K.; Solimando, L. \& Goldman, R. D. Nuclear lamins: major factors in the structural organization and function of the nucleus and chromatin. Genes Dev., 22(7):832-53, 2008.

Fahrenkrog, B. \& Aebi, U. The nuclear pore complex: nucleocytoplasmic transport and beyond. Nat. Rev. Mol. Cell Biol., 4(10):757-66, 2003.

Forero, J. E. \& Urcuqui, S. Principales factores en el transporte núcleo-citoplasma: papel de Rev en el proceso del transporte de transcritos de VIH1. Colomb. Med., 35(4):214-23, 2004

Hoelz, A.; Debler, E. W. \& Blobel, G. The structure of the nuclear pore complex. Annu. Rev. Biochem., 80:613-43, 2011.

Maeshima, K.; Lino, H.; Hihara, S. \& Imamoto, N. Nuclear size, nuclear pore number and cell cycle. Nucleus, 2(2):113-8, 2011.

Montanaro, L.; Treré, D. \& Derenzini, M. Nucleolus, ribosomes, and cáncer. Am. J. Pathol., 173(2):301-10, 2008.

Paniagua, R.; Nistal, M.; Sesma. P.; Álvarez-Uría, M.; Fraile, B.; Anadón, R. \& Sáez, F. J. Biología Celular. Madrid, McGraw-Hill, 2007. pp.71-131.

Terry, L. J.; Shows, E. B. \& Wente, S. R. Crossing the nuclear envelope: hierarchical regulation of nucleocytoplasmic transport. Science, 318(5855):1412-6, 2007.

Dirección para Correspondencia:

Dr. Ricardo Cornejo

Facultad de Medicina

Universidad de La Frontera

Casilla 54-D

Temuco - CHILE

Recibido : 27-05-2015

Aceptado: 16-09-2015

Email: rene.cornejo@ufrontera.cl 